Natalia Maliutina*

Uniwersytet w Białymstoku

https://orcid.org/0000-0002-5787-2753

\title{
Психотерапевтический дискурс в современной русской драме
}

Аннотация: В статье проанализированы коммуникативные стратегии высказывания в ряде пьес современных русскоязычных драматургов (А. Строганова, Д. Балыко, А. Волошиной, О. Канина, И. Муренко) на тему психоаналитических практик, группового сеанса у психотерапевта и т. п.

Как показал анализ, в этих пьесах актуализированы процессы личностной (само)идентификации героя/читателя с Другим, механизмы манипуляции массовым сознанием, создания перформативного способа интеракции. Репрезентация внутреннего состояния героев служит средством трансформации привычной картины мира героя, возвращения к изначальному (дотравматическому) состоянию. Инкорпорированный в структуру действия сеанс психотерапии содержит мощный ресурс моделирования контрпереноса психологического состояния, в связи с чем расширяется опыт переживания той или иной роли, принятия/непринятия ее не только героем, но и читателем/зрителем как части себя.

Natalia Maliutina-dr hab., prof. UwB; literaturoznawczyni, komparatystka; pracuje na Uniwersytecie w Białymstoku; autorka takich prac jak: Проблема культурной (само)идентификации героя в новейшей постсоветской драме: переформатировка (2019; współautor), Смерть в симулятивном пространстве гиперреальности современной русской драмы (на примере пьес Олега Богаева) (2018). 
При этом в ряде пьес проявляется риторическая стратегия дидактичности, притчевости, иронии, пародии. Психотерапевтический дискурс представлен как одна из составляющих медиареальности, формирующая массовое коллективное сознание.

Ключевые слова: психоаналитический дискурс, репрезентация, референция, идентификация.

\section{Psychotherapeutic Discourse in Contemporary Russian Drama}

Summary: The article analyzes the communicative strategies of the utterance in a number of plays by contemporary Russian-speaking playwrights (A. Stroganov, D. Balyko, A. Voloshinoy, O. Kanina, I. Murenko) on psychoanalytic practices, group sessions with a psychotherapist, etc.

As the analysis has shown, these plays reveal the processes of personal (self)identification of the hero/reader with the Other, the mechanisms of manipulation with the mass consciousness and the creation of a performative way of interaction. The representation of the hero's internal state serves as a means of transformation of his habitual picture of the world as well as a way of returning to the initial (pre-traumatic) state. The psychotherapy session incorporated into the structure of the action contains a powerful resource for modeling the countertransference of the psychological state. Hence, the background of experiencing a particular role, accepting it or not by the hero and also by the reader/spectator as part of themselves expands.

At the same time, a number of plays demonstrate a rhetorical strategy of didacticism, parables, irony and parody. The psychotherapeutic discourse is presented as one of the components of media realism that forms the mass collective consciousness.

Key words: psychoanalytic discourse, representation, reference, identification.

\section{Dyskurs psychoterapeutyczny we współczesnym dramacie rosyjskim}

Streszczenie: Artykuł analizuje komunikacyjne strategie wypowiedzi w szeregu przedstawień współczesnych dramaturgów rosyjskojęzycznych (A. Stroganowa, D. Balyko, A. Voloshinoy, O. Kanina, I. Murenko) dotyczą- 
cych praktyk psychoanalitycznych, sesji grupowych z psychoterapeutą itp. Jak pokazała analiza, spektakle te ujawniają procesy (samo)utożsamiania się bohatera/czytelnika z Innym, mechanizmy manipulacji świadomością zbiorową i kreowania performatywnego sposobu interakcji. Reprezentacja stanu wewnętrznego bohatera służy transformacji jego zwyczajowego obrazu świata, a także jest sposobem na powrót do stanu wyjściowego (sprzed traumy). Sesja psychoterapeutyczna wkomponowana w strukturę działania zawiera skuteczne sposoby modelowania stanu psychicznego. Stąd poszerza się tło przeżywania określonej roli, lub nie przez bohatera, a także przez czytelnika/widza jako część siebie. Równocześnie w szeregu spektakli ukazuje się retoryczna strategia dydaktyzmu, przypowieści, ironii i parodii. Dyskurs psychoterapeutyczny jest przedstawiany jako jeden z elementów realizmu medialnego kształtującego zbiorową świadomość zbiorową.

Słowa-klucze: dyskurs psychoanalityczny, reprezentacja, odniesienie, identyfikacja.

В современной русской драме все активнее проявляют себя способ высказывания, коммуникативные стратегии, позволяющие осуществляться психотерапевтической практике либо моделирующие ее. При этом речь не идет о текстах, написанных и актуализируемых как сценарии психотерапевтических (чаще групповых коллективных) практик. Подобный опыт давно закреплен в психологии и психиатрии, в тех методах взаимодействия с пациентами, которые предполагают определенные средства воздействия арттерапии на сознание и действия той группы людей, поведение которых подвергается психокоррекции ${ }^{1}$.

1 Подобные сценарии психологического воздействия, психокоррекции пользуются немалой популярностью, прежде всего, в практике психотерапевтов, арт- и драмотерапевтов, осуществляющих лечение пациентов. Так, в качестве примера можно привести психотерапевтические пьесы (авторское название) известного российского психотерапевта, основоположника научной школы «Терапия творческим самовыражением» (его монография с таким же названием вышла в 1989 году) Марка Бурно. Это пьесы, специально написанные им для Реалистического психотерапевтического театра и опубликованные в специальных научных изданиях (напр., М. Бурно, Бедолаги (психотерапевтическая пьеса в 2-х действиях), „Психотерапия”, 2017, № 9 (177), s. 2-13). 
В связи с этим буду опираться на исследования психоаналитиков, арттерапевтов, психологов, культурологов, драматургов, у которых разработаны подходы к психодраматической терапии в различных аспектах ${ }^{2}$. Наиболее близким предлагаемому анализу поэтики драматургии считаю явление психодрамы, убедительно представленное и апробированное в научных работах и психотерапевтической практике Якоба Морено, Грете Лейтс и др. Безусловно, отождествлять психотерапевтический дискурс в драме, психодраму и психоанализ не стоит даже в случае анализа определенных техник или методов. Но при этом их внутренняя связь очевидна и осмыслена, прежде всего в психоаналитических исследованиях ${ }^{3}$.

Стоит подчеркнуть, что «драматический» компонент понимается в этих исследованиях не как театральность представления, а, скорее, как «ролевая гибкость», способность не только воспроизведения травматического опыта, но и эмпатического перепроживания ситуаций, которые не осуществились по тем или иным причинам в жизни да и не могли осуществиться ${ }^{4}$. Благодаря участию условного пациента в психодраме как ее героя, ее творца, а также исследователя себя и своей жизни, он осуществляет технику вчуствования, переноса, теле-проекций (трансферов), в том значении, которое придавали этим понятиям Якоб Морено и Грете Лейтс. Исследователи и практики психодрамы использовали огромный перформативный ресурс, обнаруженный в ней как в своеобразном коллективном действе, что можно использовать для анализа современной русской драматургии, в которой концептуализируется психотерапевтический дискурс. При этом учитываем когнитивные паттерны, распознающиеся в поэтике высказывания, заложенную драматургом способность в процессе разыгрывания пьесы распознать Другого в себе (в своей роли), а также креативного воспроизведения ситуации, изменяющего отношение к осознанной проблеме.

2 Прежде всего, речь идет о работах Я. Морено, Г. Лейтс, Д. Каппера и др.

3 Стоит обратиться к статье обобщающего характера по этому вопросу Игоря Кадырова. И. Кадыров, Психодрама и психоанализ: два театра для психической драмы, „Московский психотерапевтический журнал”, 1996, № 1, http:psyjournals.ru (Дата обращения: 1.08.2019).

4 Г. Лейтс, Психодрама: теория и практика. Классическая психодрама Я. Л. Морено, M., 2007. 
Вполне понятно, что в своих практиках и теоретических прогнозах психотерапевты, арт- и драмотерапевты используют базовый инструментарий, подходы и методики театроведения и драмоведения как научных дисциплин и художественных явлений. Тем не менее, психоаналитический научный и практический потенциал также является значительным ресурсом для изучения тех современных пьес, в которых так или иначе представлен психотерапевтический дискурс. Это направление исследования разрабатывали в свое время Николай Евреинов, Ежи Гротовский, Антонен Арто, Константин Станиславский и др. При этом психотерапевтический дискурс в драме как в художественном тексте исследован значительно меньше, что и побуждает предметно проанализировать это явление с учетом новых научных тенденций в области коммуникативных стратегий, ролевых игр, репрезентативно - референтных маркеров высказывания. Общим полем психотерапевтического дискурса и высказывания как поэтикального представления картины мира в драме является референция к коллективному бессознательному и индивидуальному поведению субъекта действия (и говорения). Кроме того, таким общим планом и инструментом изучения может служить феномен воображения, актуализированный в виде метафор, метонимий, различных переносов смыслов, сновидений, галлюцинаций и др. Не случайно давно и широко исследованы возможности метафоры (метонимии) как семиотического ресурса психоаналитического метода и текста драмы (театра) 5 .

Объектом исследования в статье станут художественные пьесы, прежде всего, предназначенные для постановки в театре. Особый интерес представляют коммуникативные стратегии высказывания в таких пьесах, авторами которых являются как драматурги, одновременно реализующие себя в сфере психологии, психотерапии, так и те, для кого эта тема в ряду других просто служит средством художественной условности и способом высказывания.

5 В связи с этим стоит обратиться к научным исследованиям М. Блэка, Э. Джордан, Н. Арутюновой, Т. Липской и др., посвященных проблемам структурирования опыта посредством метафор, самодвижения метафоры, ее способности к пробуждению творческих ресурсов воображения, личностного самосознания и др. Стоит вспомнить, что роль метафоры в психодраме также изучалась в работах бразильского режиссера Аугусто Боаля, основателя «Театра Угнетенных», театральной практики, связанной с явлением освобождения (смотри Радуга желания: театр и терапия, метод Боаля, Лондон 1995). 
Используя категорию коммуникативные стратегии, следую за мыслью Валерия Тюпы о том, что с точки зрения коммуникативного поведения автора любой «...драматургически упорядоченный текст является репрезентативом», который создает и преобразует ситуацию общения ${ }^{6}$.

Во время чтения или сценической интерпретации пьес, прежде всего, возникает ситуация совместного переживания опыта, в результате которой конституируется модель межсубъектного общения, возможность поделиться совместно приобретенным опытом пребывания в данном месте и пространстве 7 . При этом имагинативно возникшие образы не только изображаются, но и так или иначе репрезентируются вербальными и невербальными средствами. Подобно тому, как и в психодраме, в пьесах современных русских драматургов актуализируется связь образов, предшествующих высказыванию, представлений, реакций, с коллективным и индивидуальным бессознательным.

Стоит отметить, что психотерапевтический и психоаналитический дискурс драмы обусловлен самой природой, а точнее, семиосферой психоанализа и драмы (театра). Не случайно под психоаналитическим сеансом современные исследователи понимают часто «...драматургию смыслопорождения, в которой инерционное сопротивление открытию нового смысла, вызванное желанием избежать повторной травмы и боли, дополняется общей семиотической сопротивляемостью пациента..» ${ }^{8}$.

Зачастую действие в современной русской драме напоминает (имитирует) психоаналитические практики, психотерапевтический сеанс. В творчестве драматургов - психотерапевтов, например, белорусской русскоязычной писательницы Дианы Балыко и барнаульского автора Александра Строганова тема коррекции психики нередко создает контрапункт поэтики их разных по жанрам и коммуникативным стратегиям пьес.

Созданная барнаульским драматургом-психотерапевтом Александром Строгановым теория трансдраматической терапии базируется на разраs. 172 .

В. Тюпа, Дискурснье формации, Очерки по компаративной риторике, М., 2010,

7 Tamże, s. 173.

8 Ф. Филатов, Семиосфера психоанализа, „Russian Psychological journal”, 2014, vol.11, S. 3 . 
ботанных Б. Брехтом, К. Станиславским, М. Чеховым и других деятелей театра приемах ролевой трансформации отношений: психотерапевт (режиссер) - пациент (актер) и наоборот ${ }^{9}$.

«Драмотерапия» направлена на выработку новых ощущений своего «Я» в связи с обнаружением дистанции от роли, а, возможно, и слияния с ней, с экспериментами в сфере межличностного взаимодействия ${ }^{10}$.

Важно отметить, что пьесы А. Строганова имеют сложную, основанную на метатеатральных принципах, форму.

Рассмотрим пьесу «Павлы», в которой можно обнаружить прямую референцию к психоаналитическим практикам и, даже, отношениям между врачом и пациентами онкологического отделения больницы. Действие пьесы представляет собой бесконечное варьирование роли «Павла Андреевича», исполняемой одновременно и последовательно четырьмя пациентами онкологического центра и врачом с теми же именем и отчеством. Создается сценарий, в котором используется ситуация идентификации: происходит дифференциация и трансформация поведенческих реакций, эмоций, ролевых реакций в поведенческой ситуации, определяемой вопросом: как это быть врачом по имени Павел Андреевич в палате, где находятся четверо онкологических больных с теми же именем / отчеством.

Вместе с тем, все персонажи пьесы: и врач, и пациенты стремятся обрести дистанцию от исполняемой ими роли, выражать истинные чувства и тем самым осознать свою индивидуальность.

Эта ситуация напоминает расстройство сознания - диссоциативное расстройство идентичности - синдром множественной личности.

К пьесе прилагается жанровый подзаголовок: «Стансы в двух действиях». Кроме того, что в тексте пьесы в исполнении одного из пациентов - Павла Андреевича Дрозда - звучат стансы А. С. Пушкина «Ты мне велишь пылать душою...», композиция напоминает строфическую форму станс - относительно законченные по смыслу строфы-картины.

Шесть картин (три - в первом действии и три - во втором действии) озаглавлены автором так, что в названии можно найти подсказку,

9 А. Строганов, Психотерапия на базе театральных систем. Практическое руководство, СПб., 2008.

10 Tamże, s. 84. 
какая психоаналитическая практика моделируется (или проигрывается) в ней.

В первой картине («Мехраб») врач Павел Андреевич Буеносов обнаруживает в своем бессознательном четыре «дракона»-двойника по ассоциации с пациентами палаты. Во второй картине «Кукольный театр» актуализируется практика перевода реальных явлений и объектов (в том числе и человеческого организма) на язык кукольного театра.

В картине третьей «Первая любовь» разыгрывается практика, содержащая в себе эффект Эдипова комплекса. У всех пациентов палаты обнаруживаются рудименты младенческих переживаний: Дрозд Павел Андреевич сообщает, что его рвет от молока, а Потапов Павел Андреевич говорит, что при воспоминании о женщинах у него начинает интенсивно выделяться слюна.

Первая картина Второго действия под названием «Пиленбургер» связана с практикой идентификации неизлечимых больных с теми животными, у которых никогда не бывает этих болезней ${ }^{11}$.

Пятая картина под названием «Таити» позволяет представить практику выявления и вытеснения из подсознания фобий, в частности, страха перед сексуальными отношениями.

Кульминацией шестой картины («Кварцевание») становится появление медсестры с чистым бельем: она перестилает постель умершего во время операции юного Лапушкина Павла Андреевича и кварцует палату. В списке действующих лиц сказано, что ему не многим более двадцати лет, он не произносит в пьесе ни одного слова. В этой картине проигрывается практика перевода бессознательного в область сознательного.

В репликах персонажей (условных Павлов) и будущего психолога, а сейчас санитарки Евы, неоднократно вариируется интерпретация фразы апостола Павла из Второго Послания коринфянам о том, что видимое временно, а невидимое - вечно («Когда мы смотрим не на видимое, но на невидимое, ибо видимое временно, а невидимое вечно»).

Пациентам Павлам приходится осознать, что в видимом мире они лишь фигуры в распоряжении судьбы (рока), а в невидимом - уже игроки. В том невидимом мире у них, как утверждает Дрозд, будут другие

11 Речь идет о теории Пауля Ульриха Пиленбургера. 
имена (Дрозд «... И у нас есть другие имена , о которых мы пока ничего не знаем, но непременно узнаем позже») ${ }^{12}$.

Практики визуальной (само)идентификации театрализируются в пьесе, обретают сценическую (театральную) форму в сцене-картине «Кукольный театр», в которой врач Буеносов показывает свой «михраб» в морге: поломанные куклы, части от кукол, явно связанные с операциями врача). Можно предположить, что себя и пациентов он давно воспринимает в качестве подобных кукол. Таким образом, реализуется контрперенос своего психологического состояния на других (на кукол, символизирующих мир пациентов) $)^{13}$.

При подобном психическом состоянии вызывается механизм психологической защиты, когда человек начинает воспринимать происходящее с ним так, будто это происходит с кем-то другим. В переводе на язык театра - осуществляется брехтовский эффект отчуждения, а на языке психоанализа - контрперенос ${ }^{14}$. Возникает еще одно отчуждение (в воображаемом театре представлений героев): мира видимых явлений, сущностей и не видимых ... воображаемых представлений.

Дрозд. У кошек, и у собак там в невидимом совсем другие настоящие имена. Не те, что мы здесь, наугад присваиваем им. Настоящие имена. Улавливаешь !.. Какой-нибудь Шарик - на самом деле Феликс или Эхнатон ... И у нас есть другие имена, о которых мы пока ничего не знаем, но непременно узнаем позже.

Потапов. Когда ?

Дрозд. Когда перейдем в категорию невидимого ${ }^{15}$.

Таким образом, следует отметить, что психоаналитические практики, закодированные в сфере художественной образности (напр., в виде

12 А. Строганов, Павль. Стансы в двух действиях, www.theatre-library.ru (дата обращения: 13.08.2019).

13 Как отмечает Паула Хайман в статье «О контрпереносе», аналитик прорабатывает в ходе анализа свои инфантильные конфликты и тревоги, тем самым получает ключ к бессознательному пациента. Таким образом, пациент передает или проецирует на аналитика роли Ид, Эго и Суперэго, а также роль внешних объектов в процессе драматизации своих конфликтов в ходе аналитических взаимоотношений. П. Хайман, О контрпереносе (пер. с англ. Е. Смирновой), Антология современного психоанализа. Т.1 (red. А. Россохина), М., 2000, s. 142-147.

14 Tamże.

15 А. Строганов, Павль ..., dz. cyt. 
метафор и метонимий) образы, референция к которым распознается в семиотическом пространстве пьесы, воплощены в структуру метафорического контрпереноса, характерного приема психотерапии. Высказывание при этом репрезентирует процессы идентификации себя с Другим, с ролью, с метафорой и т.п.

Достаточно часто в современных пьесах русскоязычных драматургов уже в самом названии распознается тема психотерапевтического сеанса, что само по себе передает коммуникативные стратегии автора. Так в пьесе драматурга и психолога из Белоруссии Дианы Балыко «Психоаналитик для психоаналитика» (2005) действие представляет собой цепь событий, отсылающих к реальным практикам психоаналитических сеансов. В основе перипетий пьесы - ряд симуляций: герои, обратившиеся к мнимому психоаналитику, играют во влюбленность, в этой паре девушка использовала партнера для решения своих психологических проблем. Да и мнимый психоаналитик, Вера Андреевна, обратившаяся за помощью к настоящему психоаналитику Альберту, получает вместо любви бонусный сеанс психоанализа. Таким образом в легкой развлекательной комедийной форме автор иронизирует над стереотипами психоаналитических сеансов и репрезентирует игру как способ существования в мире симулякров.

В названии еще одной «серьезной комедии» Игоря Муренко «Клад крем или прием ведет психолог» заложены смыслы пародийного остранения штампов психологического анализа ${ }^{16}$. В этой пьесе пациентами психолога стала молодая супружеская пара, которая в результате общения с психологом пересмотрела свое отношение друг к другу: метафорически оформленная неосознанная мысль о смерти и погребении супруга (и затем - своей собственной) трансформировалась в результате сеансов в искреннее чувство друг к другу. Еще одной парой пациентов - конкурентов по бизнесу - стали Директор кладбища и Директор крематория.

16 Как омечается автором в аннотации к пьесе, в ней использованы методы: нейролингвистического программирования, гипноза американского психотерапевта Милтона Эриксона, психокоррекции российского психотерапевта Эрика Берна, динамической медитации индийского учителя - мистика Бхагавана Шри Раджниша (Ошо), техника остановки мысли (Квантовое смещение) американского психотерапевта Фрэнка Кинслоу https://www.proza.ru (Дата обращения: 27.07.2019). 
Их стремление к вытеснению позиций конкурента сменилось дружеским сближением. В процессе приема психолога выявилась все большая потребность самого врача в подобной помощи. Типичные ситуации послужили, по-видимому, для драматурга своеобразным способом риторического проявления собственной позиции. Не случайно в этой пародийно-иронической комедии два (столь же избитых, много раз тиражированных) финала. Для стационарного театра и для антрепризы. В одном - все герои погибают в результате взрыва во время кремации Психолога и их души встречаются в пространстве тонких энергий, а во втором - появляется Представитель криогенной кампании с предложениями по сохранению тела. Подобные финалы комедий рассматриваются в контексте массовой популярной литературы как определенный способ авторской интерпретации, а, значит, и коммуникативных стратегий, в основе которых - представление о возможности манипуляции сознанием при помощи терапевтических практик, такие стратегии могут быть направлены на процессы (само)идентификации у реципиентов. Этому служит прогнозируемая эмоциональная реакция читателя / зрителя, для которого авторская ремарка об использованных психоаналитических техниках в пьесе является средством убеждения в том, что текст пьесы «вписывается» в контекст новейших научных исследований в области психоанализа, но, вместе с тем, создает яркий иронический контраст с примитивно развивающимся действием и слабо мотивированным поведением и высказываниями героев. Можно думать, что психотерапия может рассматриваться как одно из составляющих мощной медиаиндустрии, формирующей современное массовое сознание и манипулирующее ним.

Несколько иные коммуникативные стратегии и художественные ресурсы распознаются в пьесах современных русских драматургов Аси Волошиной «Пациенты» (2015) и Олега Канина (2913) «Без нас». В обеих пьесах также актуализирован метатеатральный формат психоаналитических практик, реализуемых посредством художественных средств: репрезентации и / или перформатизации образного мира в высказывании, а также визуализации, посредством которой в поэтике действия осуществляются роли психотерапевта и пациента. Зачастую те и другие меняются местами.

Действие пьесы Аси Волошиной «Пациенты» (2015) разворачивается в частной клинике для людей с психоневрологическими аномалиями 
(подобными тем, которые описаны в книге Оливера Сакса «Галлюцинации»). Среди них патология правого полушария головного мозга, старческая деменция, ретроградная амнезия, синдром проприоцепции, при котором тело как бы утрачивает память и теряется представление о его положении в пространстве. В лечебнице для пациентов с психиатрическими заболеваниями, возможно, воображаемых, находится известный кинорежиссер Ион Бертран ${ }^{17}$, который постепенно теряет память и движимый своим страхом забыть любимую им умершую жену, решает снять фильм, в котором пациенты станут персонажами, неожиданно осознавшими свой страх. Так, одна из пациенток по имени Агнешка, утратившая ощущение своей правой стороны, смогла увидеть ее в зеркало и пережить шок, подобный смерти. С ней происходит утрата привычной (само)идентификации.

Высказывания пьесы подчеркнуто аллюзийны: в тексте пьесы есть посвящение известным неврологу, нейропсихологу, посвятившему себя исследованиям повреждений коры и подкорковых структур головного мозга, Оливеру Саксу, и кинорежиссеру - сюрреалисту Луису Бунюэлю, в фильмах которого «оживают» процессы подсознательного.

В диалогах (возможно, воображаемых Ионом) персонажей сливаются воедино референтное слово (обращенное к произведениям О. Сакса и Л. Бунюэля, а, точнее, к способам восприятия мира и сознания, представленным в них) и репрезентативное, которое представляет ситуацию общения, вызванного называнием болезни, ее метафизическими истоками, представленными в качестве образов - ассоциаций в сознании персонажа. Говоря о репрезентативности или репрезентативах, вслед за В. Тюпой, имеем ввиду коммуникативное событие имитации речи актантов, процесса размышления, в результате которого не констатируется нечто происходящее, но мыслится как действие («миметическая репрезентация перформативов $)^{18}$.

Репрезентация, по наблюдениям В. Тюпы, противостоит перформативности, поскольку самопроизводящая речь в качестве действия (пер-

17 Янн Артюс-Бертран, французский кинорежиссер, сценарист, актер, продюсер, создавший фильмы «Планета-океан», «Марокко с высоты птичьего полета» и др.

18 В. Тюпа, Нарратив и другие регистры говорения, „Narratorium”, 2011, № 1-2, http:narratorium.rggu.ru (Дата обращения: 8.08.2019). 
формации) конституирует, «развертывает собой» (М. Эпштейн) процессы мысли, сознания ${ }^{19}$.

Один из (воображаемых) пациентов Штурм наделяет всех остальных пациентов ролями, наполняя их действия возможными историями, придающими диалогам характер художественной репрезентации. Так, например, поняв, что психика одного из пациентов, Джонни, реагирует на его страх («помнить погибшего сына»), он открывает Иону способность мозга достраивать утраченное сознание.

Штурм. Итак ... А, да, последнее. Хочу напомнить Вам, что психика Джонни достраивает образ, цепляясь за детали. А теперь...подержитека это ${ }^{20}$.

Штурм показывает Джонни репродукцию известной картины Ганса Гольбейна (в этой ситуации опять-же осуществлен принцип репрезентации - Н. М.), на которой изображен Христос, снятый с креста ${ }^{21}$. Джонни узнает на ней своего погибшего сына.

В последних сценах пьесы значительно усиливается перформативный посыл высказываний: одна из (воображаемых) пациенток Маша всячески заставляет Иона снимать страхи других, прежде всего, страх Агнешки. Таким образом она как бы пытается ее убить, тем самым убеждая Иона в том, что она (Маша) - его жена. Ион утрачивает способность к личностной (само)идентификации, утрачивает последние привычные ощущения, за которые как бы «удерживалось» его «Я», понимая, что не любит эту вдруг возникшую перед ним жену. Усиливается способность высказывания вызывать действие. Даже нарушения грамматических правил в речи Агнешки (например, она говорит: «Пусть все будет проваливаться») способствуют конституированию ее автокоммуникации, автореферентного содержания ее реплик.

Маша. Я теперь могу быть кем хочу. Можешь усмехаться сколько нравится, раз этот мир лишил меня моей жизни и моего тела ...

19 Tamże.

20 А. Волошина, Пацчиенты, пьеса в 2-x д, https: //moc.media.files.bs... (Дата обращения: 4.08.2019).

21 Само появление картины в высказывании Штурма содержит аллюзию к известной сцене из романа Ф. М. Достоевского «Идиот». Увидев у Рогожина эту картину, князь Мышкин произнес фразу о том, что, глядя на нее, вера может вообще пропасть. 
Шторм. Всего лишь пропрецепции ...

Маша. Тела ! Я могу взять взамен чужую жизнь. Пусть все будет проваливаться.

Итак, репрезентация своего состояния пациентами может рассматриваться как попытка уйти от себя, обрести личностную (само)идентификацию в общении (иногда - насильственном - Н. М.) с Другим. В аннотации к пьесе Ася Волошина отметила, что пьеса «Пациенты» - о том, как герои волей или не волей прячутся от себя и своей судьбы. При этом они сталкиваются с роком и каждый из них может стать посланцем рока для кого-то другого 22.

Врач, о котором говорят пациенты в пьесе, оказывается внесценическим персонажем, так что все действия по репрезентации своего состояния и попытке его преодолеть (что оказывается актом идентификации по модели обретения своего «Я» в Другом) совершаются в сознании пациентов. Можно предположить, что Ион Бертран наделен чертами Демиурга, в его перформативных съемках страхов Других, трансформируются не только их, но и Его сознание. Для кого-то возможность увидеть осознание страха Другого несет эффект возвращения к себе прошлому: мозг вытесняет программу забывания (как у Джонни), для кого-то, например, для Миссис О’Нилл (взглянув в зеркало во время съемки, она навсегда утратила привычное представление о себе), Маши, Агнешки да и самого Иоанна взгляд своему или чужому страху «в лицо» означает утрату себя.

Ион (Маше). Я не помню тебя! Это пришло. Я смотрю в твое лицо и не могу его вспомнить. Я ничего не чувствую !23

Для него потеряла всякий смысл даже возможность увидеть свой фильм глазами любимой женщины (на ее роль претендует не лишенная эгоистических целей Маша). Таким образом, исчезают заменяющие реальность «ментальные протезы» 24 .

22 http: www.mythos.spb.ru [20.07.2020].

23 А. Волошина, Пациентыл ..., dz. cyt.

24 Использую метафору из книги Оливера Сакса «Галлюцинации» (М., 2014). Психолог, в частности, пишет о том, что мозг создает галлюцинации как «ментальные протезы», чтобы помочь справиться с глухотой, слепотой... 
Важно отметить, что читатель / зритель воспринимает в пьесе референцию к способу восприятия мира и сознания, тем самым формируется опыт обращения к исходной фазе (структуре чувственного переживания) самосознания. Стоит подчеркнуть, что этот опыт хоть и реализуется в сфере образного мира, но в процессе его обретения воображаемый мир художественных образов и способ восприятия мира условно отделяются. Думаю, что механизмы пробуждения личностной (само)идентификации становятся значительным ресурсом перформативного опыта в процессе рецепции текста пьесы. При этом возникает ситуация удвоения референции высказывания, что связано с эффектом театрализации.

Не случайно во многих пьесах, напоминающих по сценарию сеанс психотерапии или психоаналитических практик, как отмечалось, используется метатеатральный формат развития действия.

Зачастую, как в пьесе Олега Канина «Без нас» (2013), - это пространство театра, в котором собираются четыре пациента, страдающие различными психическими расстройствами, страхами, вызванными шоком. Психолог Самойлов приглашает их принять участие в сеансе психотерапии, чтобы, высказавшись, проиграв еще раз некогда пережитый страх, боль, ужас, пациенты сами смогли себе помочь.

Каждая рассказанная и вновь пережитая пациентом история помещена автором в определенный культурно-когнитивный контекст со знаком не -, задающий вектор интерпретации каждой автокоммуникативной ситуации. В первой сцене-ситуации под названием «Эффект бабочки» проигрывается рассказ инфантильной девушки Кати о том, как тотальный страх несостоятельности перед будущим привел ее к психосоматической проблеме: непроходимой головной боли. Вторая сцена «Не Родион Раскольников» содержит сценарий пережитой Тимуром сцены аффекта из-за осознания своего не-героизма, страха перед отчислением из института, в результате чего он выстрелил в себя. В основе третьей сцены («Поворот не туда») - комплекс вины: герой Антон из-за роковой случайности становится убийцей: переезжает человека. В четвертой сцене («Моцарт») реализуется психокомплекс жертвы: прорывается агрессия, направленная на объект фрустрации девушки Лизы: ее фортепиано. Каждая история неотделима в сознании реципиента от известных нарративов. В связи с этим реализуется стратегия деконструкции текста, субъективная 
интерпретация пережитого вступает в конфликт с культурными стереотипами, базовыми знаниями читателя / зрителя. В высказываниях персонажей и в авторских ремарках реализуется риторическая стратегия воздействия на сознание реципиента путем демонстрации опыта общения, опыта переживания той или иной травмы или «примеривания» субъективного восприятия героев к базовым стереотипам.

Утратив инициатора психологических практик (Психотерапевта), четверо пациентов начинают интенсивно помогать друг другу. Читатель, зритель равным образом получает сценарий театральных практик преодоления фобии, боли, того или иного комплекса. Высказанная и пережитая вновь история служит моделью референтного действия.

Проанализированные пьесы позволяют сделать некоторые выводы о коммуникативных стратегиях драматургов, сознательно тематизирующих психотерапевтические практики в форме театрального действия.

Художественная образность пьесы А. Строганова «Павлы» лишена дидактически- притчевого начала в артикуляции высказывания. В ней как бы «снимается» роль психотерапевта. Театральное действие разыгрывается в образной сфере нашего сознания и подсознания, что напоминает сюрреалистические эксперименты. Актуализируется стратегия перевоплощения, трансформации, при этом читатель, зритель в своем сотворчестве наполняет эту протеичную образную магму контекстами и значениями.

В пьесах же Аси Волошиной и Олега Канина репрезентативность как характеристика высказывания, указывающая на отношение дискурса к действительности, позволяет выявить риторические стратегии: в пьесах проявляется модальность знания, понимания, примера, что сообщает высказыванию некоторую дидактичность и притчевость. Адресату предлагается выстроенная автором картина мира, как обобщенное риторическое пространство межличностного взаимодействия. В этом смысле в подобных пьесах содержится мощный коммуникативный ресурс референции, формирующий модель поведения как взаимодействия, конвенциональность зрительского участия. Риторически репрезентирован Голос (маска) Психотерапевта, при этом образность наделяется референтным значением в рамках определенной ситуации, модели мира, например, сеанса психотерапии. 


\section{Литература}

Антология современного психоанализа. Т.1 (под ред. А. Рассохина), М., 2000.

Волошина А., Пациенты, пьеса в 2-х действиях, режим доступа: http: www. theatre-library.ru [20.07.2020].

Кадыров И., Психодрама и психоанализ: два театра для психологической драмы, „Консультативная психология и психотерапия”, 1996, № 1.

Канин О., Без нас, пьеса в 2-х действиях, режим доступа: http: www.theatrelibrary.ru [20.07.2020].

Лейтс Г., Психодрама: теория и практика, Классическая психодрама Я. Л. Морено, М., 2007.

Сакс О., Галлюцинации, М., 2014.

Строганов А., Психотерапия на базе театральных систем, М., 2008.

Строганов А., Павлы. Стансы в 2-х действиях, режим доступа: http: www. theatre- library.ru [20.07.2020].

Тюпа В., Дискурсные формации. Очерки по компаративной риторике, М., 2010.

Тюпа В., Нарратив и другие регистры говорения, „Narratorium”, 2011, № $1-2$.

Филатов Ф., Семиосфера психоанализа: постановка проблемы, „Russion Psychological Journal", 2014, vol. 11, № 3.

\section{Bibliografia}

Antolohyia sovremennoho psykhoanalyza. T.1 (pod red. A. Rassokhyna), M., 2000.

Fylatov F., Semyosfera psykhoanalyza: postanovka problemy, „Russion Psychological Journal", 2014, vol . 11, № 3.

Kadyrov Y., Psykhodrama y psykhoanalyz: dva teatra dlia psykholohycheskoi dramy, „Konsultatyvnaia psykholohyia y psykhoterapyia”, 1996, № 1.

Kanyn O., Bez nas / http: www.theatre-library.ru [20.07.2020].

Leits H., Psykhodrama: teoryia y praktyka, Klassycheskaia psykhodrama Ya. L. Moreno, M., 2007.

Saks O., Halliutsynatsyy, M., 2014.

Strohanov A., Pavly. Stansy v 2-kh deistvyiakh, http: www.theatre-library.ru [20.07.2020]. 
Strohanov A., Psykhoterapyia na baze teatralnykh system, M., 2008.

Tiupa V., Dyskursnye formatsyy. Ocherky po komparatyvnoi rytoryke, M., 2010.

Tiupa V., Narratyv y druhye rehystry hovorenyia, „Narratorium”, 2011, № 1-2.

Voloshyna A., Patsyenty, pesa v 2-kh deistvyiakh, http: www.theatre-library.ru 